\title{
Outbreak of Covid19 Disease: Is It Resultant of Our Voraciousness?
}

\author{
Saif Ullah Munshi \\ Chairman \& Professor, Department of Virology, Bangabandhu Sheikh Mujib Medical University, Dhaka, Bangladesh
}

[Received: 26 March 2020; Accepted: 2 April 2020; Published: 25 April 2020]

The researchers have identified over 250 foodborne diseases, most of which are due to pathogens like; bacteria, viruses, and parasites. There are many human behaviors, which bring civilization into contact with the communicable pathogens carried by wildlife. This can be caused by infringement of human activity into wild forest areas or by movement of wild animals into human locality. It is assumed that among 177 human pathogens, which are regarded as originated from non-human animals called 'Emerging' among which $73.0 \%$ are zoonotic ${ }^{1}$. Zoonosis is a matter of concern because these are often unrecognized diseases or have increased virulence in populations lacking immunity. Some emerging diseases are caused by viruses like measles, smallpox, influenza, HIV, SARS-CoV, MERS and SARS-CoV-2 had broken species barrier. All these viruses caused a global epidemic or pandemic situation. Of many of the human diseases, the human is an accidental victim and a dead-end host.

Most human prehistory was spent as groups of hunter-gatherers when usually around 150 persons lived in a society. At that time, most or all food were obtained by searching for wild resources. The oldest hominins who were probably mostly bipedal, inhabited in woodlands and were likely fed on fruit, eggs and small creatures. The later hominins were fully bipedal and they started eating meat. The first Homo species known to emerge was Homo habili, which hereditary had the ability to use and manipulate stone tools. Migration of Homo spp. out of the African homeland to other parts of the world started as early as 1.8 million years ago, which is directly linked to the supply and availability of foodstuffs. It involved the invention and use of specialized instruments, technologies, and approaches for hunting, such as the development of fishing tools or the collaborative hunting of large game. The transition from an omnivorous diet of Homo spp. to carnivorous shaped it toward a predator-prey interface which helped in the acquisition of pathogens of prey in human, such as Helminthes, Viruses, Bacteria. This shows the close interactions between Homo spp. and other primates likely occurred, potentially including predation and intake of primate meat. The settlement of human population in the new Stone Age when Homo sapiens changed from mobile hunter gatherers to settled village farmers, contributed to development of agriculture and farming, and domestication of various plant and animal species as food and feed resources. This domestication of plant and animals associated with the handling and storage of food, prompted intimate \& continual interaction between humans and husbandry practices generated crowded conditions for domestic livestock, facilitates the emergence, spread and evolution of infectious pathogens within these species.

Thus, human development has been developing a relation with zoonosis. This zoonosis which occurred because of maintenance of food chain driven by voraciousness of human being, at some point of time causes disease outbreak leading to epidemic and pandemic situation. These epidemic or pandemic diseases, which depend on a constant influx of infected humans to the non-immune population, had a tendency to knock out after their first run through the non-immune population. Early humans may have suffered sporadic cases of animal-borne diseases, such as anthrax from wild sheep or tularemia from wild rabbits $^{2}$, but the domestication of animals around 10,000 years ago likely provided the highest medium for zoonotic 
disease transmission ${ }^{2}$. Humans and our ancestors have likely killed wild animals for consumption as bushmeat for millions of years which include antelopes, chimpanzees, fruit bats, rats, snakes, hedgehogs, porcupines, civets, etc. Consumption of bushmeat is an ancient \& primordial practice in tropical countries and it is increasingly used to sustain human population. In recent time, the commercial hunting using firearms and wire snares has dramatically increased the hunting of wild animals in the forests of different parts of the world. The extensive range of tissue and fluid exposures associated with the busmeat industry has been associated with the contraction of diseases.

According to the Centre of International Forestry Research (CIFOR), people eat about 5 million tonnes of bushmeat per year only in Africa's Congo Basin $^{3}$. It is believed that in 2014 Ebola outbreak occurred in the Congo Basin because of consumption of bushmeat. The family of the first infant who died of Ebola stated that they had hunted two species of bat which are reservoirs of the Ebola virus. However, $30.0 \%$ of all previous human Ebola virus outbreaks had sparked not from the reservoir species rather by handling of Ebola-infected ape carcasses. Similar Crossing Species Boundaries of virus while butchering of Simian Immunodeficiency (SIV)-infected chimpanzees is also postulated for transmission of Human immunodeficiency virus (HIV) which is ravaging the entire world. SIV has been reported in 26 species of African non-human primates, many of which are hunted and traded as food.

During the year 2002 to 2003, severe acute respiratory syndrome coronavirus (SARS-CoV) affected 8422 people and caused 916 deaths in China. This virus was originated in horseshoe bats which crossed over to humans via the intermediary host of palm civet cats which were sold in the wet markets in Guangdong province near Hong Kong as a source of meat ${ }^{4}$. The same thing happened in Wuhan in 2019, the capital and largest city in Hubei province of China, SARS-CoV-2 symptoms that is later linked to the Huanan Seafood Market, which sells fish and shellfish, but also wild game like beavers, porcupines and snakes. It's still not clear in what animal SARS-CoV-2 originated. The closest known wildlife sequence to SARS-CoV-2 remains the sequence from the virus isolated from a horseshoe bat (>95\% homology). Malayan pangolins have been proposed as potential intermediate hosts, and SARS-CoV-2 like viruses have been identified in pangolins seized in antismuggling operations in southern China.
Now questions come why people in different parts of the country eat these creatures? Though in the remote areas like Africa, hunting on animal is an important source of meat but in other localities it has turned into a delicacy. In China, these creatures are consumed for delight, nourishment and their unsupported medicinal qualities. There are traditional Chinese ideas about the potential of certain food, which have promoted some unhealthy habits. Snake soup is a famous dish in Guangdong region of China especially in cold as it is viewed to have the influence in warming up the heart. Snakes and rats are frequently consumed in countries like Thailand, Indonesia, Laos, Myanmar, the Philippines, Indonesia, Vietnam, China and Cambodia and West Africa, Ghana and other countries. In the USA, cooked rattlesnake meat is a common dish in the American Midwest. Civet cats are a local delicacy in southern China, but they are also associated with one of the most exclusive coffees in the world - Kopi luwak of Indonesia which consists of partly digested coffee cherries that have been eaten and defecated by the Asian palm civet cat.

Though some of its practices are folkloreish or esoteric, the concept is pervasive among the Chinese people who don't follow them. These animal meat is also exported from different countries to the western world to serve as delicate cuisine. It was estimated in 2004 that the total volume of illegal meat entering Great Britain each year is on average to be 11,875 tone. The source of these meat includes snake, antelope, frogs' legs, snails, and cows' nostrils, as well as meat from endangered species such as chimpanzees and elephants.

Beside the bushmeat, farming of livestock, poultry and wild animals has become a greater source of zoonotic disease causing disease outbreak. Because of urbanization \& increasing incomes, the per capita consumption of meat, eggs and dairy products have dramatically increased in the developing world, leading to revolution in livestock and poultry. These industries are influencing the changing evolution of avian influenza. Avian influenza refers to the disease caused by infection with bird influenza Type A viruses. These viruses occur naturally among wild aquatic birds worldwide and can infect domestic poultry and other bird and animal species. It is thought that the greater the number of potential zoonotic influenza hosts the greater the risk of zoonotic influenza transmission. In addition, the indiscriminate use of antibiotics in these sectors for improvisation of feed efficiency causing drug resistant zoonotic Bacterial infection. The use of 
ruminant meat and bone meal in diet of broiler chickens has increased the chance of infection of prion diseases.

Another crucial factor contributing to the appearance of new zoonotic pathogens in human populations is increased contact between humans and wildlife while farming animals. An example of this is the outbreak of Nipah virus in Malaysia in 1999, when intensive pig farming began on the habitat of infected fruit bats.

Food security is a fundamental human right. People kill the wildlife as a source of food and trade their body parts. This habit and cultures are driven by the people's voraciousness. We demand to stop these sorts of activities. The societies which are involved in such action should be discouraged from eating the animals which are risking our life by producing disease outbreak. Wildlife hunting for food is important for the supply of dietary protein for poor people. To halt this, we require alleviating poverty, improve food security, enhance our development efforts. We should increase access to affordable and reliable alternative sources of animal protein such as chicken, small livestock and farmed fish for those who are consuming the wild animals as their food. There is an urgent need of strengthening and enforcement of wildlife conservation laws and safeguard wild life of the protected areas.

To limit this bushmeat hunting for business in markets, political decision of each government is extremely essential. In the context of COVID-19 pandemic, the Chinese government has banned the trade and consumption of wildlife animals since February' 2020 and released a draft list of animals that can be farmed for meat and fur, including domesticated animals.
Though there are rules surrounding the export and import of wild game, and an international agreement prohibits or limits international commercial trade of vulnerable wildlife; these are actually not abided by. Therefore, we urge the global community to enforce the rules and regulation to end the killing of wild creatures as a source of food and save the whole world from future disease outbreaks.

\section{References}

1. Woolhouse ME, Gowtage-Sequeria S. Host range and emerging and reemerging pathogens. Emerging Infectious Diseases. 2005;11(12):1842

2. Weber DJ, Rutala WA. Zoonotic infections. Occupational medicine (Philadelphia, Pa.). 1999;14(2):247-84

3. Cooney D. Center for International Forestry Research (CIFOR). Interview: Ebola and bushmeat in Africa: Q\&A with leading researcher. Published on: 2 September 2014; Viewed on: 12 March 2020] Website: https://forestsnews.cifor.org/23924/ebola-andbushmeat-in-africa-qa-with-leading-researcher?fnl=

4. Hu, B., Ge, X., Wang, L. et al. Bat origin of human coronaviruses. Virol J 2015;12;221

[Bangladesh Journal of Infectious Diseases, April 2020;7(suppl_1):S63-S65]

Correspondence: Prof. Dr. Saif Ullah Munshi, Chairman \& Professor, Department of Virology, Bangabandhu Sheikh Mujib Medical University, Shahbag, Dhaka, Bangladesh; Email: saifmunshi@yahoo.com; saifmunshi@bsmmu.edu.bd; Cell no.: +8801711376343

Conflict of Interest: Author has no competing interests.

How to cite this article: Munshi SU. Outbreak of Covid19 Disease: Is It Resultant of Our Voraciousness? Bangladesh J Infect Dis 2020;7(suppl_1):S63-S65

Copyright: $\odot 2020$. Munshi. Published by Bangladesh Journal of Infectious Diseases. This article is published under the Creative Commons CC BY-NC License (https://creativecommons.org/licenses/by-nc/4.0/). This license permits use, distribution and reproduction in any medium, provided the original work is properly cited, and is not used for commercial purposes 